\title{
Modelling the impact of pulsing of drip irrigation on the water and salinity dynamics in soil in relation to water uptake by an almond tree
}

\author{
V. Phogat ${ }^{1}$, M. A. Skewes ${ }^{1}$, J. W. Cox ${ }^{1,2}$ \& M. Mahadevan ${ }^{1}$ \\ ${ }^{1}$ South Australian Research and Development Institute, Australia \\ ${ }^{2}$ The University of Adelaide, Australia
}

\begin{abstract}
Pulsing is the application of daily irrigation in a phased manner involving one hour irrigation and one hour off. A field experiment was conducted involving pulsed and continuous irrigation to almonds through surface drip during 200910 , and water applications and moisture distribution in the soil were monitored throughout the season. A finite element numerical model (HYDRUS 2D) was used to evaluate the impact of pulsed application of irrigation on water balance and salinity distribution in the soil. The modelled values of moisture content matched well with the weekly measured neutron probe values at all soil depths $(10 \mathrm{~cm}$ to $160 \mathrm{~cm})$ with RMSE of mean values varying from 0.01 to 0.08 and 0.01 to 0.05 in pulsing (Ip) and continuous (Ic) treatments respectively. The simulated seasonal water uptake was slightly higher $(25 \mathrm{~mm})$ in pulsing than continuous irrigation, whereas the soil storage was slightly higher (20 $\mathrm{mm})$ under continuous irrigation. The leaching fraction amounts to 0.25 in both treatments and was higher during August and March-April because the water requirement of almond early in the growing season and after harvest remained relatively low. The salinity distribution was similar in both treatments and simulated average salinity of soil solution varied from 0.47 to $3.38 \mathrm{dS} / \mathrm{m}$ and 0.49 to $3.67 \mathrm{dS} / \mathrm{m}$ in Ip and Ic treatments respectively. Hence the modelling simulations revealed that pulsed irrigation at higher discharge rate $(3.87 \mathrm{l} / \mathrm{h})$ produced similar water and salinity distribution in the soil as obtained in low discharge $(2 \mathrm{l} / \mathrm{h})$ continuous
\end{abstract}


irrigation. These outcomes can be utilized to improve irrigation efficiency and system design for drip irrigation of almonds.

Keywords: modelling, pulsing, almond, drip irrigation, moisture content, salinity, water uptake, leaching, HYDRUS 2D.

\section{Introduction}

Irrigation management under a high-frequency drip system involves controlling the quantity of water passing through the root zone. This is achieved by regulating the trickle discharge rate according to the soil hydraulic properties. This practice minimised deep percolation and leaching of nutrients and other chemicals from the root zone. One of the fundamental objectives of drip irrigation is to lower the application rate to match plant water uptake as closely as possible in order to improve irrigation efficiency. However, due to some technical limitations (e.g. discharge and operation pressure, clogging) application of low discharge rates is problematic [1]. There are spatial and application interventions that can be used in drip irrigation, such as pulsing of water, which may produce similar moisture and solute distribution in the soil to using low discharge rates. Pulsing is composed of a series of irrigation cycles where each cycle is composed of an irrigation phase and a resting phase.

Short duration (10 to $24 \mathrm{hr}$ ) modelling studies $[1,2]$ found that pulsed irrigation produced similar water content regimes to micro drip and slightly increased the wetted radius and depth compared with continuous irrigation. However, Elmaloglou and Diamantopoulos [3] reported a deeper wetting front for pulsed than for continuous irrigation with the same application depth. Skaggs et al. [4] observed a small increase in the horizontal spread of moisture under pulsing compared with continuous irrigation, which was the result of water dissipating during the redistribution phase following irrigation. Phogat et al. [5] reported that pulsing had little impact on moisture and salinity distribution, leaching fraction and salt removal in soil under almond during the profile establishment period (i.e. the initial wetting up phase of the soil). It is, however, unclear from these studies whether the impact of pulsing would be of any practical benefit on a long term basis, considering plant uptake and the interaction of all fluxes across the soil boundaries over the entire irrigation season.

The present investigation involves the use of HYDRUS-2D simulations run using field data recorded for an almond tree over an irrigation season. The aim was to evaluate the impact of pulsing and slow discharge continuous drip irrigation on the dynamics of water fluxes including plant water uptake, deep drainage and salinity distribution in the soil.

\section{Materials and methods}

\subsection{Field experiment}

The experiment was conducted at Clark Taylor Farms, a commercial almond [Prunus dulcis (Mill.) Webb] orchard in Berri, South Australia (34 $20^{\prime} \mathrm{S}$ and 
$140^{\circ} 35^{\prime} \mathrm{E}$ ) from July 2009 to May 2010. The orchard was planted in 1998 with the rows oriented roughly north-south with a spacing of $6.7 \mathrm{~m}$ between rows and $6.1 \mathrm{~m}$ within rows. The Almond variety Nonpareil (50\%) was considered for the experiment, but it was inter-planted with Carmel $(33 \%)$ in alternate rows and with Ne Plus Ultra $(17 \%)$ at every $6^{\text {th }}$ row, both as pollinators. All trees were grafted on to Nemaguard root stock. Soil samples were taken from various depths $(0-30,30-60,60-90,90-150 \mathrm{~cm})$ at the start of the experiment and analysed for physical properties. Since the soil was more or less uniform to 150 $\mathrm{cm}$ depth, a mean soil particle size distribution of $89 \%$ sand, $2 \%$ silt, $9 \%$ clay and a bulk density of $1.61 \mathrm{~kg} / \mathrm{m}^{3}$ were considered for this study. The trees were managed and fertilized following current commercial practices.

The climate at the site is Mediterranean, characterized by warm to hot, dry summers and mild to cold winters. The total rainfall received during the study period was $220 \mathrm{~mm}$. A Class-A evaporation pan $\left(\mathrm{E}_{\mathrm{pan}}\right)$ was used to measure daily evaporation. Daily ETc was calculated from $\mathrm{E}_{\mathrm{pan}}$ values of the previous day multiplied by a suitable crop factor [6].

The orchard was surface drip irrigated, with pulsed (Ip) and continuous (Ic) irrigation treatments covering an area of 1.89 and 0.7 ha, respectively. Water for irrigation was pumped directly from the River Murray with a separate water meter installed for each treatment to measure the volume of water applied. The salinity of the irrigation water ranged between 0.2 and $0.52 \mathrm{dS} / \mathrm{m}$, which is well within the permissible limit for irrigation.

Each row of trees was served by two dripper laterals, one on either side of the tree row at $1 \mathrm{~m}$ offset from the tree trunks. The pulsed treatment (Ip) was irrigated with a cycle of one hour on and one hour off, repeated until the same volume was applied as in the continuous (Ic) treatment. The average flow rate of the drippers was $3.9 \mathrm{l} / \mathrm{h}$ and $2.0 \mathrm{l} / \mathrm{h}$ for Ip and Ic treatments, respectively. The dripper distance in these treatments were $100 \mathrm{~cm}$ and $80 \mathrm{~cm}$, respectively. Neutron probe access tubes were installed at 0,20, 40, 60, 80 and $100 \mathrm{~cm}$ lateral distance from the dripper to a depth of $160 \mathrm{~cm}$, to monitor profile soil water distribution. Measurements were conducted at weekly intervals (fig. 1) at every $10 \mathrm{~cm}$ depth up to $100 \mathrm{~cm}$, and every $20 \mathrm{~cm}$ between $100 \mathrm{~cm}$ and $160 \mathrm{~cm}$.

\subsection{Numerical modelling}

Soil water and salinity distributions below the drip line were simulated with the computer simulation model HYDRUS2.xx [7]. In this model, the twodimensional water flow is described by a modified form of Richard's equation and advection-dispersion equation is incorporated for the simulation of the transport of a single non-reactive ion in homogeneous medium. The equations are explained in user's manual [7] of the model and were not reproduced here for brevity. The soil hydraulic parameters were modelled using the water retention and hydraulic conductivity function described by the van Genuchten-Mualem constitutive relationship $[9,10]$. 


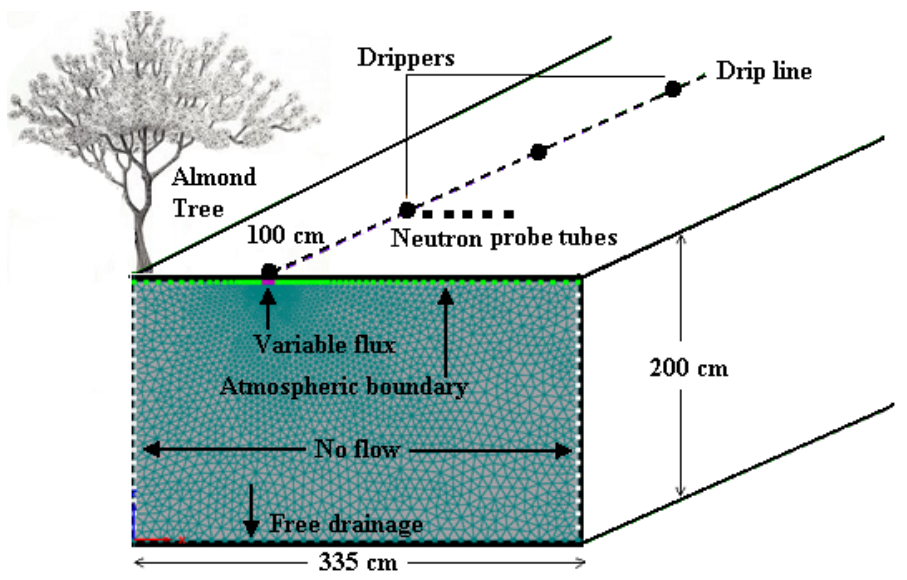

Figure 1: A schematic view of model domain with imposed boundary conditions, plant spacing and monitoring equipment.

\subsection{Estimation of input parameters}

\subsubsection{Potential evaporation and transpiration}

The seasonal irrigation schedule was based on $\mathrm{E}_{\mathrm{pan}}$ and crop factors, however, the potential transpiration $\left(\mathrm{T}_{\text {pot }}\right)$ and potential evaporation $\left(\mathrm{E}_{\mathrm{s}}\right)$ were calculated from the reference evapotranspiration (ETo) values collected from the Bookpurong Meteorological Station, situated 150-200 $\mathrm{m}$ away from the experimental site, following the dual crop coefficient method [11], to serve as an input for the model. This method is based on splitting the crop coefficient $\left(\mathrm{K}_{\mathrm{c}}\right)$ into two separate coefficients, one for crop transpiration, i.e. basal crop coefficient $\left(\mathrm{K}_{\mathrm{cb}}\right)$ and one for soil evaporation $\left(\mathrm{K}_{\mathrm{e}}\right)$ as:

$$
K_{c}=\left(K_{c b}+K_{e}\right)
$$

The coefficients for the experimental period were estimated on the basis of fraction of ground cover, density and tree height. The seasonal $\mathrm{T}_{\mathrm{pot}}$ amounted to $1380 \mathrm{~mm}$ and $\mathrm{E}_{\mathrm{s}}$ for the same period was $414 \mathrm{~mm}$.

\subsubsection{Soil hydraulic parameters}

Running the model requires accurate measurement of soil hydraulic parameters viz. $\theta \mathrm{r}, \theta \mathrm{s}, \mathrm{Ks}, \alpha, \mathrm{n}$ and $\mathrm{l}$. The direct measurement of these parameters in the field or laboratory is time consuming and costly. Therefore, the hydraulic parameters were estimated using ROSETTA, a pedotransfer function software package that uses a neural network model to predict hydraulic parameters from soil texture and bulk density data. The estimates of optimised hydraulic parameters used for the modelling simulations were: $\theta \mathrm{r}=0.03 \mathrm{~cm}^{3} / \mathrm{cm}^{3}, \theta \mathrm{s}=0.4 \mathrm{~cm}^{3} / \mathrm{cm}^{3}, \mathrm{Ks}=$ $276.57 \mathrm{~cm} /$ day, $\alpha=0.0316 \mathrm{~cm}^{-1}$ and $\mathrm{n}=2.2$. The value of 1 was taken as 0.5 as recommended by Mualem [9]. 


\subsubsection{Root distribution and water uptake functions}

The almond root distribution was described [12] using the two dimensional model adapted in HYDRUS [14], and expressed as:

$$
\beta(x, z)=\left[1-\frac{z}{z_{m}}\right]\left[1-\frac{x}{x_{m}}\right] e^{-\left(\frac{p_{z}}{z_{m}}\left|z^{*}-z\right|+\frac{p_{x}}{x_{m}}\left|x^{*}-x\right|\right)}
$$

where $z_{m}$ and $x_{m}$ are the maximum width and depth of the root zone $(\mathrm{cm})$ respectively, $\mathrm{z}^{*}$ and $\mathrm{x}^{*}$ are the distances of maximum root water uptake from soil surface and from the tree in vertical and horizontal directions, respectively, and $p_{x}$ and $p_{z}$ are empirical coefficients. The parameters used in the model for almond were: $\mathrm{z}_{\mathrm{m}}=150 \mathrm{~cm}, \mathrm{z}^{*}=30 \mathrm{~cm}, \mathrm{x}_{\mathrm{m}}=335 \mathrm{~cm}, \mathrm{x}^{*}=100 \mathrm{~cm}, \mathrm{p}_{\mathrm{x}}=2.918$, $\mathrm{p}_{\mathrm{z}}=3.214$. The values of empirical coefficients were taken from Vrugt et al. [12] optimised for almond.

The reducing effects of both soil water pressure head and osmotic head on root water uptake were included, assuming their effects were multiplicative. The following parameters of the Feddes et al. [8] model were used: $\mathrm{h}_{1}=-10$, $\mathrm{h}_{2}=-25, \mathrm{~h}_{3 \max },=-500, \mathrm{~h}_{3 \min }=-800, \mathrm{~h}_{4}=-8000 \mathrm{~cm} ; \mathrm{r}_{2}, \mathrm{high}=0.5 \mathrm{~cm} / \mathrm{d}$, and $\mathrm{r}_{2}$, low $=0.1 \mathrm{~cm} / \mathrm{d}$. The parameters $\mathrm{h}_{1}-\mathrm{h}_{4}$ represent different pressure head values which affect root water uptake in the soil. The threshold model was used to described the osmotic effects using a threshold $\mathrm{EC}_{\mathrm{e}}=1.5 \mathrm{dS} / \mathrm{m}$ and a slope of $19 \%$.

\subsubsection{Solute transport parameters}

Spatial distribution of salinity in the transport domain was simulated using the convection-dispersion equation for a nonreactive tracer. Such simulations cannot account for complex processes such as precipitation or dissolution of solid phases (e.g. gypsum or calcite) or cation exchange. Molecular diffusion was ignored. Longitudinal dispersivity was considered to be $20 \mathrm{~cm}$, which is equal to one-tenth of the profile depth, and this was optimised by previous studies on solute transport in soils [2]. The simulation output included spatial and temporal variations in soil water content, soil water salinity, soil water pressure head, and the total water and salt mass in the simulated soil profile.

\subsection{Initial and boundary conditions}

The imposed boundary conditions to the flow domain are illustrated in Fig. 1, and detailed mathematical and graphical descriptions of the boundaries adapted to the two dimensional flow in the model are in Phogat et al. [5]. The imposed initial moisture content was based on neutron probe measured values, which varied from $0.05-0.08 \mathrm{~cm}^{3} / \mathrm{cm}^{3}$ in pulsed (Ip) and from $0.04-0.06 \mathrm{~cm}^{3} / \mathrm{cm}^{3}$ in continuous (Ic) drip irrigation. Initial salinity $\left(\mathrm{EC}_{\mathrm{sw}}\right)$ in the soil profile varied from 3.89-7.22 dS/m and 4.55-7.95 dS/m respectively in Ip and Ic treatments. These were based on field measurements made before the start of the experiment and were determined from measurements of the electrical conductivity saturated soil extract $\left(\mathrm{EC}_{\mathrm{e}}\right)$, the initial volumetric soil water content $\left(\theta_{\mathrm{i}}\right)$, and the saturation 
percentage (SP) of collected soil samples. The SP was $40 \%$, and the initial soil water salinity $\left(\mathrm{EC}_{\mathrm{swi}}\right)$ was calculated as:

$$
E C_{s w i}=\left[E C_{e} \times\left(\frac{S P}{100}\right) / \theta_{i}\right]
$$

Soil solution salinity $\left(\mathrm{EC}_{\mathrm{sw}}\right)$ over time at the drip boundary was taken as a series of concentration pulses equal to the measured salinity of the applied irrigation water.

The soil surface was subjected to atmospheric boundary condition with a variable flux imposed by dripper discharge, resulting in two dimensional vertical water flow. The potential transpiration $\left(T_{\text {pot }}\right)$, potential evaporation $\left(E_{s}\right)$, irrigation and rainfall were used to represent the atmospheric boundary condition. The sides perpendicular to the flow direction were "no flow" boundaries, and free drainage conditions occurred at the bottom boundary since the water table was about $20 \mathrm{~m}$ deep. For solute transport, the boundary condition representing salinity was a third-type Cauchy boundary condition that prescribed salt movement during defined irrigation intervals.

\subsection{Flow domain and simulations}

Simulations were made during a 316 day period from 20th July 2009 to 31 st May, 2010 for hourly pulsed and continuous irrigation. The simulated surface drip irrigation system design characteristics were identical to the drip systems used for the field experiment as shown in Fig. 1. The simulated model domain was $200 \mathrm{~cm}$ deep and $335 \mathrm{~cm}$ wide (one fourth of the bed spacing used for almond production; Fig. 1). The transport domain was discretized into 5087 finite elements with a very fine grid around the dripper $(0.3 \mathrm{~cm})$ and gradually increasing elements farther from the drip (up to $9.8 \mathrm{~cm}$ ). The measured salinity of irrigation water $\left(\mathrm{EC}_{\mathrm{iw}}\right)$ was used as a time variable boundary condition. Drip irrigation was simulated assuming an infinite line source, which was shown previously by Skaggs et al. [13] to be a good representation of the drip irrigation system. Observation nodes were selected at specific locations in the domain to monitor levels of soil water salinity and content with time, as simulated by the HYDRUS model.

\subsection{Statistical test}

The root mean square error (RMSE) was calculated to compare the experimental and predicted values of moisture content and salinity as:

$$
R M S E=\sqrt{\frac{1}{N} \sum_{i=1}^{N}(M i-S i)^{2}}
$$

where, Mi and Si are measured and simulated values for an output variable, and $\mathrm{N}$ is the number of observations. 


\section{Results and discussion}

\subsection{Moisture distribution}

The weekly measured and soil profile averaged moisture content in pulsed (Ip) and continuous (Ic) irrigation treatments are compared in fig. 2 . It can be seen that the temporal dynamics of moisture content distribution in pulsed and slow discharge continuous treatment were similar. The variation in the mean values of moisture content varied from $0-0.05 \mathrm{~cm}^{3} / \mathrm{cm}^{3}$, but most of the values fall within the range 0 to $0.03 \mathrm{~cm}^{3} / \mathrm{cm}^{3}$, which is equivalent to the standard error often recorded in the field measurements of moisture content by neutron probe [14]. This implies that irrigation by pulsed rather than continuous application did not produce a measureable difference in total soil water content over the course of the irrigation season.

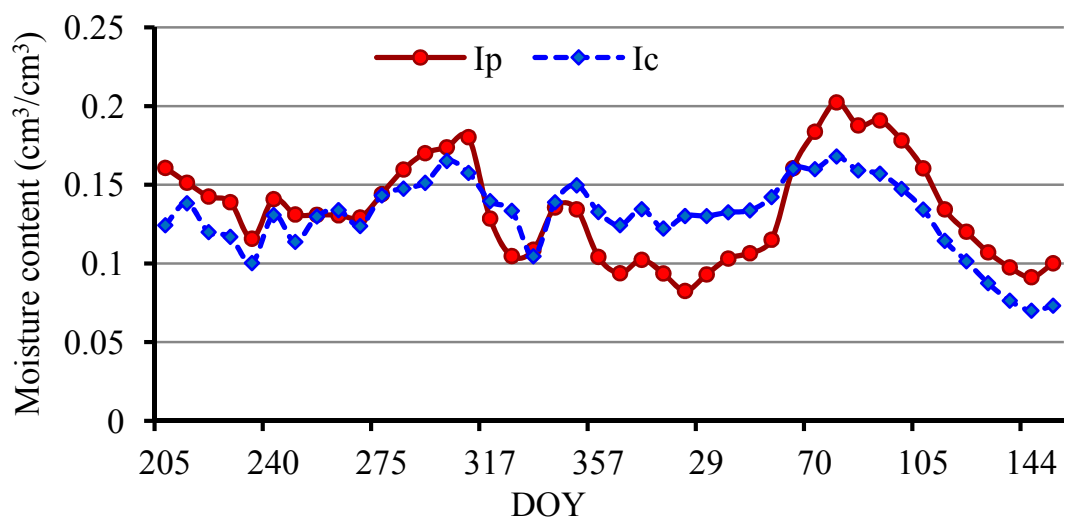

Figure 2: Weekly measured and soil profile averaged moisture content distribution in pulsed (Ip) and continuous (Ic) irrigation treatments.

Measured moisture content were compared with simulated values at all distances $(0,20,40,60,80$ and $100 \mathrm{~cm})$ from the dripper and all soil depths $(10$, $20,30,40,50,60,70,80,90,100,120,140$ and $160 \mathrm{~cm}$ ) in both treatments. For example, the measured and simulated moisture content in pulsed treatment (Ip) at $20 \mathrm{~cm}$ from the dripper, averaged for all depths is illustrated in fig. 3. The simulated moisture content values are similar to the neutron probe measured data. The RMSE values between measured and simulated values ranged from 0.01 to $0.08 \mathrm{~cm}^{3} / \mathrm{cm}^{3}$ and 0.01 to $0.05 \mathrm{~cm}^{3} / \mathrm{cm}^{3}$ in Ip and Ic treatments respectively.

Similar variation between measured and simulated moisture regimes has also been reported in other modelling studies [4, 5, 14]. This comparison confirms that the model successfully captured the dynamics of water application and movement in the soil throughout the cropping season under both scenarios of water application. However, the small differences between measured and 


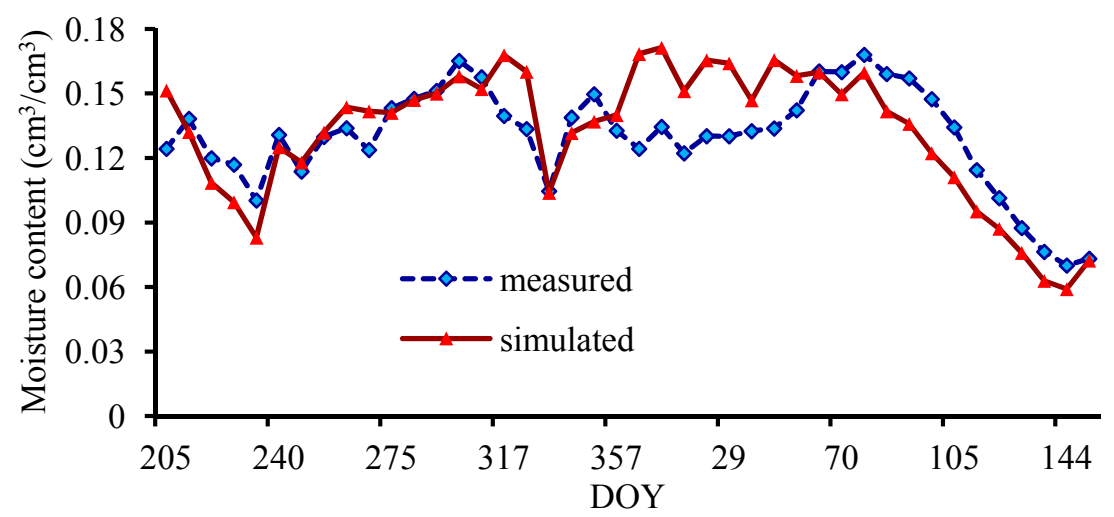

Figure 3: The comparison of weekly measured and simulated moisture content in Ic at $20 \mathrm{~cm}$ from the dripper, averaged for all depths.

simulated water content values are likely due to model errors caused by restrictive assumptions regarding the geometry of the rooting system, homogeneity of soil hydraulic properties within the spatial domain, and the prescribed root water uptake model.

\subsection{Water balance components}

The seasonal water balance components under an almond tree obtained from the modelling simulations in different treatments are shown in table 1. The seasonal water uptake by almond under pulsed (Ip) and slow discharge continuous (Ic) irrigation were almost equal, and the small variation $(2.4 \%)$ in uptake is insignificant and would have no practical implications in the context of seasonal water uptake. This observation supports the earlier assumption that soil moisture regimes similar to those resulting from continual low water application rates can be achieved by means of pulsed drip irrigation [15].

Similarly the seasonal evaporation was the same in both treatments. However, deep drainage was slightly higher $(13 \mathrm{~mm}, 2.7 \%)$ under pulsing (Ip), and soil

Table 1: $\quad$ Simulated water balance components in pulsed (Ip) and continuous (Ic) drip irrigation of almond.

\begin{tabular}{|c|c|c|c|c|}
\hline Parameters & Ip & Ic & \multicolumn{2}{|c|}{ Difference } \\
\hline & $----------------(m m)----------~$ & $(\%)$ \\
\hline Irrigation & 1686 & 1668 & -18 & 1.1 \\
\hline Rainfall & 220 & 220 & - & - \\
\hline Root water uptake & 1051 & 1026 & -25 & 2.4 \\
\hline Evaporation & 310 & 311 & 1 & 0.3 \\
\hline Deep drainage & 489 & 476 & -13 & 2.7 \\
\hline Soil storage & 53 & 73 & 20 & 37.7 \\
\hline
\end{tabular}


storage change was higher $(20 \mathrm{~mm}, 37.7 \%)$ under continuous irrigation (Ic). The apparently large changes in soil storage $(53$ and $73 \mathrm{~mm})$ reflect the depth of soil included in the model domain $(200 \mathrm{~cm})$, and the fact that the soil was quite dry at the beginning of the simulation, and uniformly wet across the model domain at the end of the simulation, as the result of irrigation and rainfall events.

Simulated daily water uptake under pulsed and continuous irrigation is shown in fig. 4. It can be seen that the daily root uptake was not affected by pulsing, remaining almost equal to that observed in the continuous treatment. An exception was slightly higher uptake under pulsing during the mid season, which had very little impact on total seasonal uptake. When water uptake under continuous irrigation is plotted against pulsed irrigation (fig. 5), the very strong relationship between the two data sets was obtained $\left(\mathrm{R}^{2}=0.99\right)$, with uptake under pulsing being slightly higher $(2 \%)$ than under continuous irrigation.

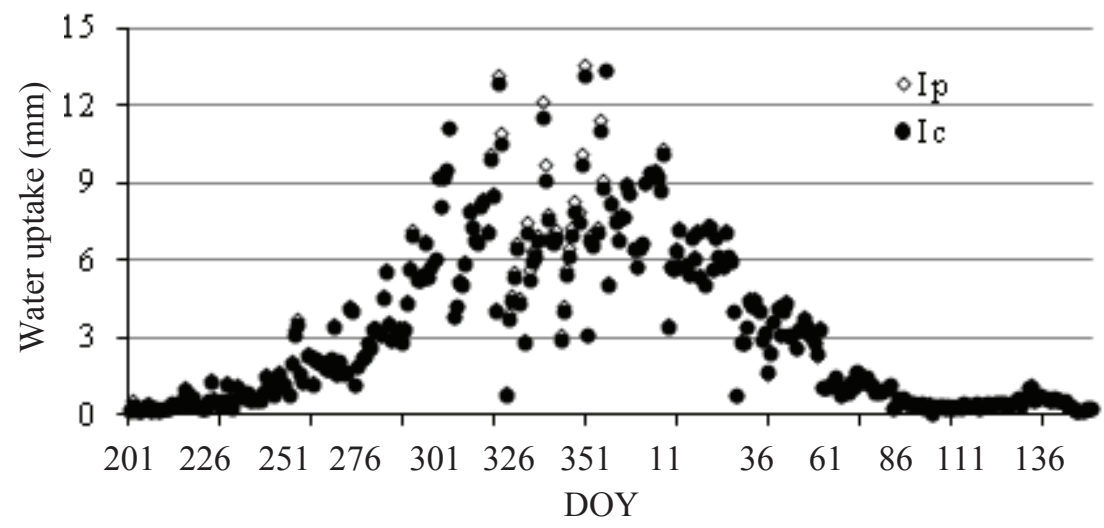

Figure 4: Comparison of simulated daily water uptake by almond tree under pulsed (Ip) and continuous (Ic) drip irrigation.

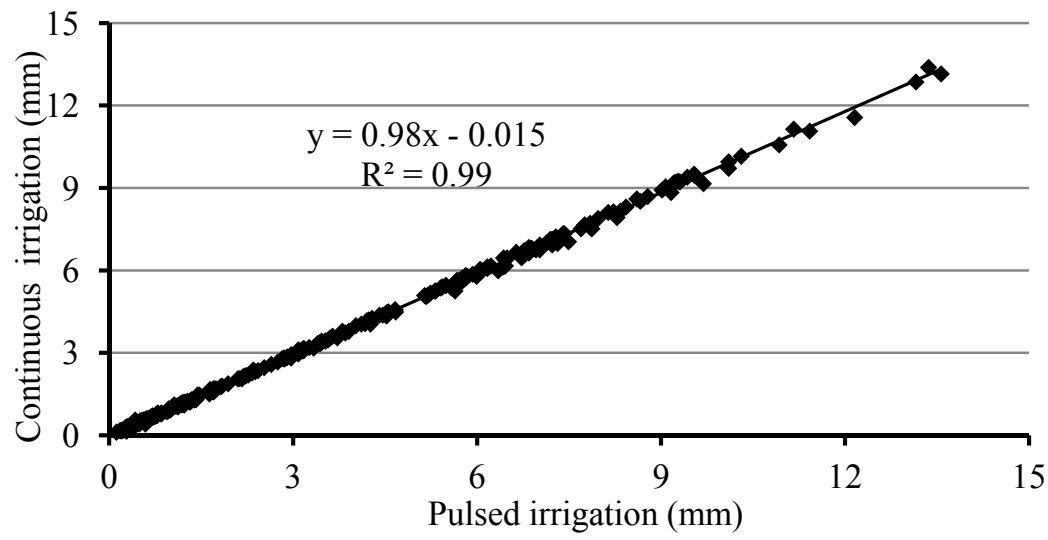

Figure 5: Regression between daily root water uptake in continuous and pulsed irrigation. 
These results indicate that water uptake by almond under high discharge pulsed water application is very similar to that under low discharge continuous irrigation. Skaggs et al. [4] and Phogat et al. [5] reported that any impact of an application sequence or application rate on horizontal and vertical advancement of the wetting front in soil was eliminated after the redistribution period following irrigation. Hence, plant roots do not discriminate how water has been applied within an irrigation event, but extract water in response to atmospheric demand, to the degree that it available. Hence similar water uptake was observed in both treatments in the present study. Although the experimental results are for a single almond tree, it is expected that the pattern of water uptake will be similar across the orchard.

Deep drainage accounted for $25 \%$ of the total water applied in both treatments. However, the leaching was not evenly distributed over the season. There was higher leaching early in the season (August) and after harvest in March-April (fig. 6), together amounting to $50 \%$ of the total seasonal leaching in both treatments. During these periods the water requirement of almond was less than the water application. This implies that there is a need to revise the crop coefficients $\left(\mathrm{K}_{\mathrm{c}}\right)$ used, and reschedule irrigation applications during these periods so that these unnecessary water losses can be controlled. This would appreciably enhance water productivity and irrigation efficiency.

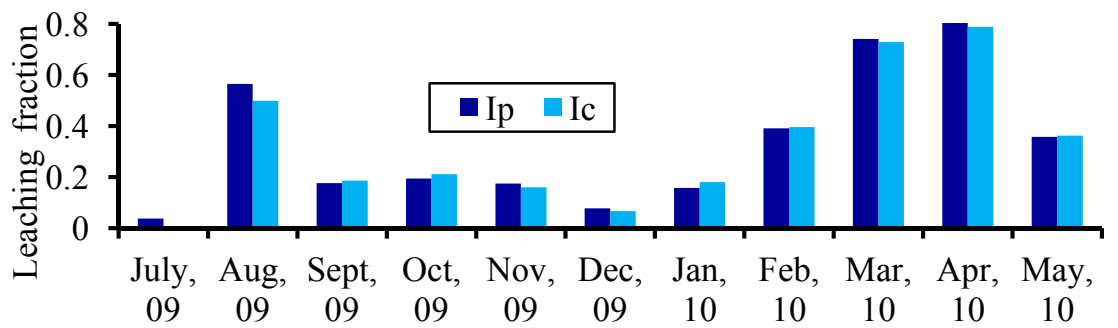

Figure 6: Monthly leaching fraction obtained in pulsed (Ip) and continuous (Ic) irrigation of almond.

\subsection{Salinity distribution}

Model simulations were also performed for seasonal salinity distribution in the soil profile, and average soil solution salinity $\left(\mathrm{EC}_{\mathrm{sw}}\right)$ data is presented in fig. 7. The $\mathrm{EC}_{\mathrm{sw}}$ values remained similar in both treatments because salt transport in light textured soil is predominantly governed by the dynamics of water movement. The average $\mathrm{EC}_{\mathrm{sw}}$ values in the soil below the dripper ranged from 0.47 to $3.38 \mathrm{dS} / \mathrm{m}$ and 0.49 to $3.67 \mathrm{dS} / \mathrm{m}$ in Ip and Ic treatments respectively.

The regression between continuous and pulsed treatments (fig. 8) again indicates a highly significant relationship $\left(\mathrm{R}^{2}=0.99\right)$, with salinity under continuous irrigation slightly higher $(7 \%)$. This confirms that pulsed irrigation at higher drip discharge rate produced similar salinity distribution to that obtained in slow discharge continuous irrigation. 


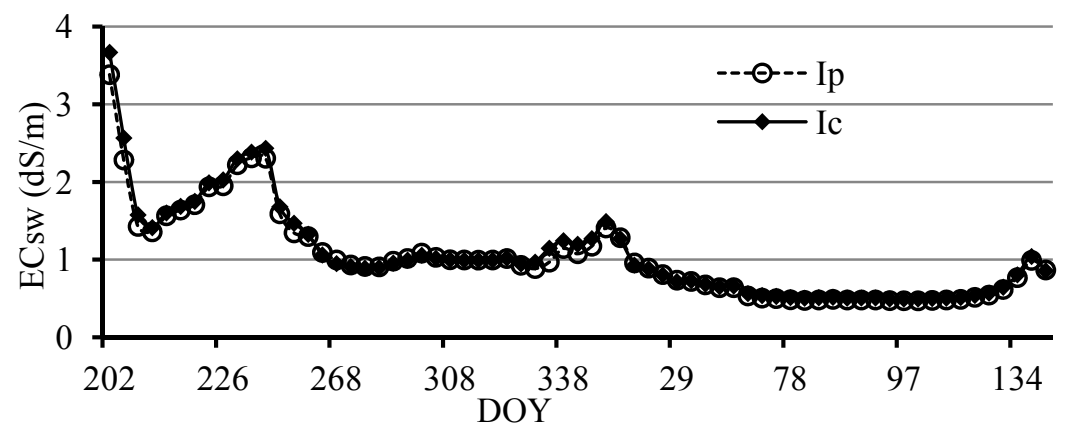

Figure 7: Simulated soil solution salinity $\left(\mathrm{EC}_{\mathrm{sw}}\right)$ distribution in pulsed (Ip) and continuous (Ic) drip irrigation of almond.

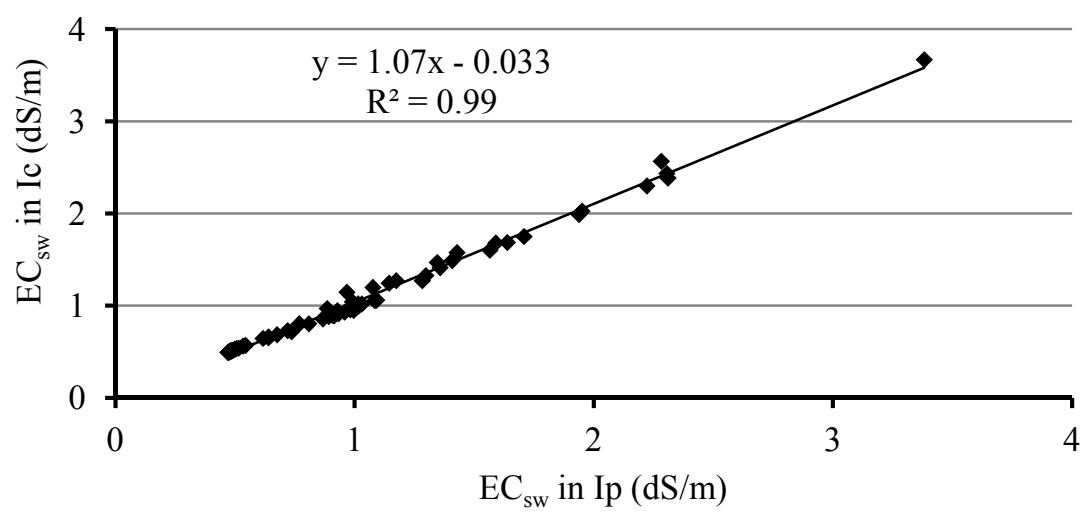

Figure 8: Regression between weekly soil solution salinity $\left(\mathrm{EC}_{\mathrm{sw}}\right)$ in pulsed (Ip) and continuous (Ic) irrigation.

\section{Conclusions}

The experimental and simulation data reported above confirm that pulsed drip irrigation with a higher discharge rate $(3.87 \mathrm{l} / \mathrm{h})$ produced a similar moisture regime and salinity distribution to low discharge $(2 \mathrm{l} / \mathrm{h})$ continuous irrigation of almond in deep sandy soil, provided that the same daily irrigation volumes were applied.

The work did identify significant drainage during the months of August, March and April, when tree water demand was less than had previously been assumed. Recalculation of crop coefficients $\left(\mathrm{K}_{\mathrm{c}}\right)$ as a result of this work has potential to lead to significant water savings and water efficiency improvements. 


\section{References}

[1] Assouline, S., Moller, M., Cohen, S., Ben-Hur, M., Grava, A., Narkis, K. and Silber, A., Soil-plant system response to pulsed drip irrigation and salinity: Bell pepper-Case study. Soil Science Society of America Journal, 70, pp. 1556-1568, 2006.

[2] Cote, C.M., Bristow, K.L., Charlesworth, P.B., Cook, F.J. and Thorburn, P.J. Analysis of soil wetting and solute transport in subsurface trickle irrigation. Irrigation Science, 22, pp. 143-156, 2003.

[3] Elmaloglou, S. and Diamantopoulos, E., Wetting front advance patterns and water losses by deep percolation under the root zone as influenced by pulsed drip irrigation. Agricultural Water Management, 90, pp. 160-163, 2007.

[4] Skaggs, T.H., Trout, T.J. and Rothfuss, Y., Drip irrigation water distribution pattern: Effects of emitter rate, pulsing and antecedent water. Soil Science Society of America Journal, 74, pp. 1886-1896, 2010.

[5] Phogat, V., Mahadevan, M., Skewes, M. and Cox, J.W., Modelling soil water and salt dynamics under pulsed and continuous surface drip irrigation of almond and implications of system design. Irrigation Science, 30(4), pp. 315-333, 2012.

[6] Almond Board of Australia (ABA), Sustainable optimisation of almond production. Reports of almond board of Australia, 2009.

[7] Šimůnek, J., van Genuchten, M.Th. and Sejna, M., The HYDRUS software package for simulating two- and three-dimensional movement of water, heat, and multiple solutes in variably-saturated media. Technical Manual, Version 2 PC Progress, Prague, Czech Republic, pp. 258, 2011.

[8] Feddes, R.A.P., Kowalik, J. and Zaradny, H., Simulation of field water use and crop yield. Simulation monographs Pudoc, Wageningen, The Netherlands, 1978.

[9] Mualem, Y., A new model for predicting the hydraulic conductivity of unsaturated porous media. Water Resources Research, 12, pp. 513-522, 1976.

[10] van Genuchten, M.Th., A closed form equation for predicting the hydraulic conductivity of unsaturated soils. Soil Science Society of America Journal, 44, pp. 892-898, 1980.

[11] Allen, R.G., Pereira, L.S., Raes, D. and Smith, M., Crop evapotranspiration guidelines for computing crop water requirements. FAO Irrigation and Drainage Paper No. 56, FAO, Rome, Italy, 1998.

[12] Vrugt, J.A., Hopmans, J.W. and Šimůnek, J., Calibration of a two dimensional root water uptake model. Soil Science Society of America Journal, 65, pp. 1027-1037, 2001.

[13] Skaggs, T.H., Trout, T.J., Šimůnek, J. and Shouse, P.J., Comparison of Hydrus 2D simulations of drip irrigation with experimental observations. Journal of Irrigation and Drainage Engineering, 130(4), pp. 304-310. 2004. 
[14] Vrugt, J.A. and van Wijk, M.T., One-, two-, and three-dimensional root water uptake functions for transient modelling. Water Resources Research, 37(10), pp. 2457-2470, 2001.

[15] Zur, B., The pulsed irrigation principle for controlled soil wetting. Soil Science, 122, pp. 282-291, 1976. 